\title{
A Randon e a sua trajetória de expansão e internacionalização
}

\author{
Armando Dalla Costa* \\ Elson Rodrigo de Souza-Santos*
}

RESUMO - Esse trabalho tem como objetivo apresentar a história do conglomerado de firmas Randon, que nasceu como uma pequena empresa familiar na cidade gaúcha de Caxias do Sul no fim dos anos 1940. Atualmente o conglomerado atua nos segmentos de implementos rodoviário-ferroviários, veículos comerciais especiais, autopeças e, em menor escala, no segmento de consórcios visando facilitar a venda de seus produtos. Hoje, possui operações nos quatro cantos do globo, inclusive com plantas industriais na China e Estados Unidos. Nesses mais de 60 anos de história, a Randon transformou-se em uma das maiores empresas privadas brasileiras através de uma bem implantada estratégia de diversificação de seus negócios e de seu processo de internacionalização.

Palavras-chave: Randon. Empresa familiar. Expansão. Internacionalização.

\section{INTRODUÇÃO}

É comum ver nas lonas que cobrem as carrocerias de boa parte das carretas a palavra "Randon" escrita em letras garrafais, que apesar de aparentar ser de uma pequena firma desconhecida de lonas é, na verdade, uma das maiores empresas privadas brasileiras que atua nos segmentos de implementos rodoviários, veículos especiais e autopeças. O conglomerado Randon nasceu no fim da década de 1940, na cidade gaúcha de Caxias do Sul, como uma pequena oficina e fábrica de freios fundada pelos irmãos Hercílio e Raul Ancelmo Randon, mas só passou a existir legalmente em 1952.

Ao longo da década de 1950 a demanda pelos serviços e produtos voltados para caminhões cresceu na região, permitindo que a Randon diversificasse e ampliasse sua gama de produtos. Na década de 1960, a empresa enfatizou a produção de semi-reboques e instalação de terceiro eixo em caminhões, simultaneamente transformou-se numa empresa com abrangência nacional, lançando sua primeira filial em Guarulhos - SP. A década de 1970 marcou o início de uma nova fase de expansão através da inauguração de nova fábrica em

\footnotetext{
* Pós Doutor pela Université de Picardie Jules Verne, Amiens, França. Doutor pela Université de Paris III (Sorbonne Nouvelle). Professor no Departamento de Economia e no Programa de Pós-Graduação em Desenvolvimento Econômico da UFPR. Coordenador do Núcleo de Pesquisa em Economia Empresarial. Endereço eletrônico: ajdcosta@ufpr.br.

** Mestrando do Programa de Pós-Graduação em Desenvolvimento Econômico pela Universidade Federal do Paraná. Endereço eletrônico: elson129@gmail.com.
} 
Caxias do Sul, a empresa também intensificou sua busca de parceiros, novas tecnologias, novos produtos, como os caminhões fora-de-estrada, e a conquista do mercado externo. Nas décadas de 1980/1990 a Randon consolidou a estratégia de joint ventures para se solidificar no mercado, diversificar suas atividades no setor de transportes e conquistar o mercado externo. Ao mesmo tempo, deu novo impulso em sua estratégia de expansão, de internacionalizar, buscando globalizar-se e dar transparência à gestão.

Este texto está organizado em três partes. A primeira trata dos antecedentes, formação e primeiros anos da Randon entre as décadas de 1940 e 1960. A segunda aborda o início da expansão, modernização e internacionalização entre as décadas de 1970 a 1990. E, por último, a visão sobre o conglomerado, enfatizando sua posição e estratégia atual, segmentos de atuação e relação com o mercado externo.

\section{ANTECEDENTES, FORMAÇÃO E PRIMEIROS ANOS}

A empresa começou na cidade gaúcha de Caxias do Sul no fim da década de 1940, ainda que informalmente, formada pelos irmãos Hercílio e Raul Anselmo Randon. Nessas seis décadas de história, a Randon passou de uma pequena mecânica e fábrica de freios de caminhões para uma das maiores firmas privadas brasileiras. Atualmente seus segmentos de atuação consistem em implementos rodoviários, veículos especiais, autopeças e uma administradora de consórcios para viabilizar a venda de seus produtos. No setor externo, mantém operações nos quatro cantos do globo, com plantas industriais nos Estados Unidos e China e parcerias com transnacionais do setor. No entanto, a Randon mantém traços de empresa familiar, pois o grupo controlador pertence à família Randon e o presidente do conglomerado é o senhor Raul Anselmo Randon, um dos irmãos fundadores.

No fim dos anos 1940, Raul Anselmo Randon deixou o serviço militar obrigatório e com o irmão Hercílio Randon passaram a dedicar-se à produção de materiais de ferraria e consertos de motores e máquinas junto às instalações da oficina do pai, Abramo Randon, partindo depois para a especialização no conserto de caminhões (RANDON, 2009). No início dos anos 1950 formaram a Randon-Rossi em sociedade com Ítalo Rossi, para a fabricação de máquinas tipográficas, destruída por um incêndio em 1951 (RANDON, 2009b). A primeira atividade dos irmãos Randon, foi dar continuidade aos negócios da família. Na época a região vivia o ciclo da madeira e os motores industriais das serrarias precisavam de constantes manutenções e consertos, principalmente considerando as dificuldades de transporte e comunicação. A formação da Randon-Rossi de máquinas tipográficas, representou a tentativa 
dos irmãos Randon de se libertarem da proteção paterna e criarem seu próprio negócio. $\mathrm{O}$ episódio do incêndio de 1951 levou os irmãos Randon a reorientarem o seu foco para caminhões, utilizando a experiência da família com motores industriais e ferragens.

A Mecânica Randon para conserto de caminhões e fábrica de freios foi montada em 1949 pelos irmãos Randon e Antônio Primo Fontebasso, este último retirando-se da sociedade dois anos depois (RANDON, 2009b), mas teve seu contrato social assinado apenas em 18 de dezembro de 1952. Em 2 de Janeiro de 1953 a empresa passou a existir formalmente (RANDON, 2009). A Mecânica Randon passou a atuar num mercado crescente na região por haver grande tráfego de caminhões, sendo a maioria das estradas ruins e de terra batida e a cidade cercada por serras, os caminhões precisavam de manutenção, especialmente em relação aos freios.

Logo nos primeiros meses os sócios obtiveram sucesso e a empresa passou a ampliar sua gama de produtos, com destaque para a fabricação de freios de semi-reboques e caminhões pesados (RANDON, 2009). Isso representou não só o crescimento da Randon motivado pelo ambiente de Caxias do Sul, mas também se conjuga com o nascimento da indústria automobilística brasileira, o crescimento da produção de caminhões e a integração rodoviária. Na década de 1960, nesse ambiente propício, segundo a Randon (2009b), a firma expandiu suas instalações, ingressando no ramo de adaptação de chassi de caminhão para uso em ônibus. Em seguida iniciou a fabricação dos primeiros semi-reboques a partir de projetos criados na própria fábrica por Hercílio Randon e logo atingiu a produção de um (1) semireboque por dia. Começara então a divisão entre as atividades dos irmãos Randon, Hercílio se dedicava a parte técnica e Raul Anselmo à administração. Ocorreram também outras mudanças, com a melhora das estradas e caminhões mais potentes, o segmento de semireboques passa a ser muito atraente para a empresa, como também, a conversão de caminhões 4 X 2 em 6 X 2 através da instalação do terceiro eixo.

Dois fatos da década de 1960 indicam que a empresa Randon estava em franco crescimento. O primeiro foi a criação da Fundação Assistencial Abramo Randon em 1963, para garantir o bem-estar dos funcionários e que levou o nome do pai dos irmãos Randon (RANDON, 2009b). O segundo foi a criação do informativo da empresa em 1969 com o objetivo de se comunicar com o público interno e externo (RANDON, 2009b). No primeiro caso, uma empresa precisa ter um tamanho considerável para justificar uma fundação para cuidar de seus empregados. No segundo, indica que a empresa conseguiu uma abrangência no mercado a ponto de precisar de um veículo para se comunicar com seus clientes. 


\section{EXPANSÃO, MODERNIZAÇÃO E INTERNACIONALIZAÇÃO}

Ao longo da década de 1960, a Randon se expandiu e passou de uma empresa regional do Rio Grande do Sul para uma das maiores produtoras de semi-reboques do Brasil. Entretanto, para viabilizar planos mais ambiciosos, em 1970 transformou-se em sociedade anônima passando a denominar-se Randon S.A. Indústria de Implementos para o Transporte e, no ano seguinte, tornou-se empresa de capital aberto, em que os irmãos Randon continuavam sócios majoritários e Raul foi eleito diretor presidente (RANDON, 2009b). Essa atitude dos irmãos Randon de transformar a firma numa sociedade anônima e abrir o capital representou o primeiro sinal de como seria sua estratégia de expansão nas décadas seguintes. Esta decisão, por um lado, facilitou a atração de investidores e, por outro, deu maior transparência a gestão para firmar parcerias e joint ventures com transnacionais do setor. Contudo, o controle do conglomerado continuou sendo da família.

Consolidando a estratégia de expansão da Randon, em 1974, foram inauguradas as novas instalações fabris em área de $263 \mathrm{mil} \mathrm{m}^{2}$, com $40 \mathrm{mil} \mathrm{m}^{2}$ de área construída. No ano seguinte, a empresa passou a se chamar Randon S.A. - Veículos e Implementos (RANDON, 2009b). Essa nova planta industrial foi um dos passos para a ampliação da gama de produtos, a abertura para o mercado externo, a busca de tecnologia e a modernização dos processos produtivos. Simultaneamente, como resultado dessa fase de expansão surgiu uma série de novos produtos como os semi-reboques, carrega-tudo para cargas indivisíveis de até 35 toneladas, terceiro eixo Tanden, semi-reboque basculante com giro de 90 graus, reboque para ônibus, caminhões fora-de-estrada Randon Kockum, semi-reboque hidráulico e semi-reboque frigorífico isotérmico (RANDON, 2009).

Dentro da estratégia de expansão da gama de produtos, em 1974, após comprar tecnologia da empresa sueca Kockum, a Randon tornou-se a primeira indústria 100\% nacional a fabricar veículos automotores no sul do país ao lançar em 28 de setembro, o caminhão fora-de-estrada RK 424 para 25 toneladas (RANDON, 2009b). Em parte, a opção por fabricar um caminhão fora-de-estrada especializado para operar em mineração era uma forma de aproveitar o aumento de tal atividade na década de 1970, incentivada principalmente pelo segundo PND (Plano Nacional de Desenvolvimento). De outro lado, a compra da tecnologia sueca serviu para alavancar toda uma evolução dos caminhões fora-de-estrada fabricados pela Randon até os dias atuais.

Em 1976 foi fundada a Randon-Nicolas fruto da associação da Randon com a francesa Nicolas, com sede no Rio de Janeiro, destinada à fabricação de plataformas com 
eixos modulados para o transporte de cargas indivisíveis de 100 a 700 toneladas (RANDON, 2009b). Essa foi a primeira associação com uma transnacional que a Randon promoveu, com características de uma joint venture, apesar de ter sido desfeita nos anos seguintes e a Randon ter se retirado desse nicho. Todos esses negócios atestam que a firma estava expandindo suas atividades, mas não negligenciou o seu principal negócio que são os semi-reboques. Para isso, em 1976, iniciou a estruturação da rede de oficinas autorizadas com mais de 70 casas no Brasil para o atendimento dos serviços de pós-venda (RANDON, 2009b). A rede serve para dar assistência aos semi-reboques Randon, devido à ampliação do mercado com a venda de cada vez mais cavalos mecânicos e o seu fortalecimento como uma empresa de abrangência nacional e líder no segmento.

Parte da estratégia de expansão da Randon era conquistar o mercado externo, no qual o primeiro passo foi a exportação de quatro semi-reboques tanques e três tanques sobre chassis para o Uruguai em 1973. O primeiro grande contrato de exportação ocorreu em 1977 ao vencer uma licitação de mais de mil semi-reboques para a Argélia (RANDON, 2009b). Este último fato atestou que os produtos Randon tinham o mesmo nível de competitividade que qualquer outra grande empresa do setor a nível mundial.

$\mathrm{Na}$ década de 1980, as joint ventures se tornaram a estratégia da Randon para repartir investimentos, incorporar tecnologias de ponta consagradas no cenário internacional, agregar novos mercados e fortalecer a posição da firma nos mercados já conquistados. Seguindo essa estratégia, em 24 de abril surgiu a Freios Master Equipamentos Automotivos Ltda., fruto da associação entre Randon e Meritor Automotive Incorporated, fabricante dos produtos de marca Rockwell (freios S Came, câmaras de serviço e de estacionamento, entre outros) (RANDON, 2009b). Essa opção da Randon tem três justificativas. A primeira era reduzir riscos em relação à tecnologia e investimentos. A segunda, neutralizar uma possível concorrente e transformá-la numa aliada e, por último, impulsionar a conquista de novos mercados com o apoio de grandes firmas internacionais do setor.

$\mathrm{Na}$ década de 1990 começou a se desenhar uma nova fase da expansão da Randon. Em 1992 iniciou-se um processo de reestruturação organizacional com a criação de novas empresas e alterações no organograma societário. A família Randon criou a DRAMD Administração e Participações Ltda que se transformou no grupo controlador do conglomerado Randon. Mesmo antes dessa reestruturação, a morte do irmão Hercílio Randon em 1986 não abalou a estrutura administrativa. A reestruturação, no entanto, serviu como garantia aos investidores e parceiros de que a firma não sofreria perigo de 
autodestruição devido a brigas familiares. Em 1999, a Randon completava seus 50 anos informais, com um quadro de 4.500 funcionários e um parque industrial superior a 190 mil metros quadrados com empresas nos segmentos de implementos e veículos especiais: a Randon S.A. Implementos e Sistemas Automotivos, Randon Argentina S.A. e Randon Veículos Ltda.; no de autopeças e sistemas automotivos: a Fras-le S.A., Freios Master Equipamentos Automotivos Ltda., Jost Brasil Sistemas Automotivos Ltda., Carrier Transicold Brasil Ltda. e Suspensys Sistemas Automotivos Ltda.; e de serviços financeiros: Randon Sistemas de Aquisição S/C Ltda (RANDON, 2009b).

\section{VISÃO ATUAL}

$\mathrm{Na}$ década de 2000, o grupo Randon incorporou a estratégia de se globalizar e internacionalizar como uma forma de se fortalecer no mercado e conquistar novos segmentos. Isso pode ser atestado pelas declarações do atual presidente e co-fundador Raul Anselmo Randon, na sua mensagem aos investidores no anuário de 2008 "recordes em todos os sentidos, metas atingidas e uma sinalização clara de que um novo ciclo está se iniciando no processo de internacionalização e globalização das Empresas Randon” (RANDON, 2009c). Outro aspecto na estratégia da Randon é a transparência na sua gestão, a ponto de atingir o Nível 1 de Governança Corporativa da BOVESPA.

A estrutura acionária do conglomerado reflete o anseio de ser uma empresa com uma gestão transparente, globalizada e internacionalizada e pode ser vista no gráfico 1 . O grupo controlador é formado pela DRAMD Administração e Participações Ltda. comandada pela família (RANDON, 2009e) cabe a tal estratégia três explicações. A primeira é retirar os conflitos familiares potencialmente desestabilizadores da firma. A segunda é manter a Randon como uma empresa familiar, além de se beneficiar com a atração de investidores nacionais e estrangeiros. Por fim, dar maior flexibilidade e transparência a gestão da empresa.

As atividades das empresas integrantes do conglomerado são descritas a seguir, separadas por segmento de atuação e baseadas nas informações da Randon (2009c). A origem da receita do conglomerado por Segmento é apresentada no gráfico 2. 
GRÁFICO 1 - ESTRUTURA ACIONÁRIA DA RANDON S.A. IMPLENTOS E PARTICIPAÇÕES EM 2008

$\square$ Grupo Controlador

Investidores Estrangeiros

$\square$ Pessoas Físicas

$\square$ Pessoas Jurídicas

$\square$ Ações em Tesouraria

$\square$ Investidores Institucionais

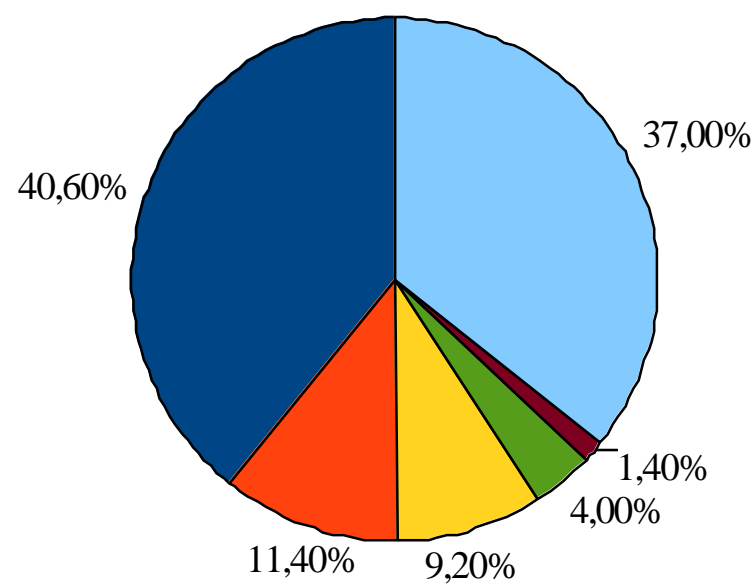

FONTE: Randon (2009d)

GRÁFICO 2 - RECEITA DO CONGLOMERADO RANDON POR SEGMENTO EM 2008

Implementos rodoviários, ferroviários e veículos especiais

Auto peças e sistemas

$\square$ Serviços e outros

FONTE: Randon (2009c, p. 13)

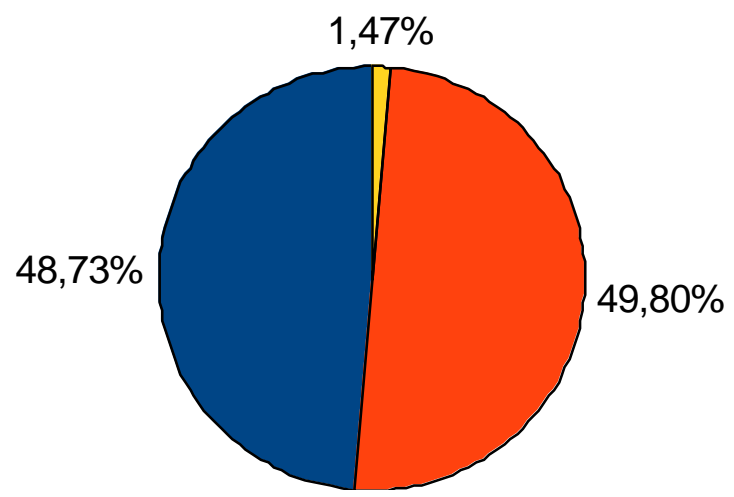

Empresas que atuam no segmento de implementos rodoviário-ferroviários e veículos especiais: Randon S.A. Implementos e Participações que produz reboques, semi-reboques e vagões ferroviários; Randon Argentina que fábrica equipamentos semelhantes; Randon Veículos Ltda. que produz caminhões fora de estrada, equipamentos florestais e retro escavadeiras.

O segmento de autopeças e sistemas que visa atender à demanda cativa da Randon Implementos e da Randon Veículos e atua como sistematizador das principais montadoras de caminhões, ônibus, reboques/semi-reboques e veículos comerciais leves instaladas no país, além de atender os setores de veículos de passageiros, aeronáuticos e ferroviários. Parcela relevante é direcionada para o mercado de reposição nacional e para o mercado externo de produtos novos e de reposição. As empresas que compõem esse segmento são: Fras-Le S.A., que produz lonas e pastilhas de freio; Master Sistemas Automotivos Ltda., que fabrica 
conjuntos de freios, utilizando os produtos da Fras-Le; Suspensys Sistemas Automotivos Ltda., que produz o conjunto de eixo e suspensão; Jost Brasil Sistemas Ltda., que faz o conjunto de articulação e acoplamento que une o cavalo mecânico ao veículo rebocado; e a CasterTech Tecnologia e Fundição Ltda. voltada à produção de componentes em ferro fundido nodular para fornecimento às empresas Randon.

O segmento de serviços é um subproduto da atuação do primeiro. Como a Randon Administradora de Consórcios Ltda. é, sobretudo, uma forma de a empresa viabilizar a venda de seus produtos, especialmente os semi-reboques, por tal motivo sua participação é tão baixa na receita da empresa.

Na tabela 1, são discriminadas as origens das receitas por empresa e a participação acionária da Randon S. A. Implementos e Participações. Dadas essas informações, é possível verificar que as empresas de implementos e veículos especiais são de propriedade quase total da Randon. Entretanto, nas empresas de autopeças, é comum a formação de joint ventures com transnacionais. Essa é uma estratégia adotada para absorver tecnologia tanto na fabricação de autopeças quanto na fabricação de implementos e veículos especiais, visto que muitos componentes são usados nessa divisão.

TABELA 1 - COMPOSIÇÃO DAS EMPRESAS DO CONGLOMERADO RANDON EM 2008

\begin{tabular}{l|r|r|r}
\hline \multicolumn{1}{c|}{ Empresa } & $\begin{array}{c}\text { Receita } \\
\text { Consolidada } \\
\text { (em mi de } \\
\text { reais) }\end{array}$ & $\begin{array}{c}\text { Receita } \\
\text { Consolidada } \\
\text { (em \%) }\end{array}$ & $\begin{array}{c}\text { Participação } \\
\text { acionária do } \\
\text { Grupo Randon } \\
\text { (em \%) }\end{array}$ \\
\hline Randon S.A Impl. E Participações (controladora) & 1.138 .406 & 37,20 & 100,00 \\
Randon Impl. P/ o Transporte Ltda. & 169.357 & 5,50 & 99,99 \\
Master Sistemas Automotivos Ltda. & 300.984 & 9,80 & 51,00 \\
Randon Veículos Ltda. & 116.396 & 3,80 & 99,99 \\
Fras-le S.A (consolidado) & 411.826 & 13,50 & 45,22 \\
Jost Brasil Sistemas Automotivos Ltda. & 150.792 & 4,90 & 51,00 \\
Suspensys Sistemas Automotivos Ltda. & 660.076 & 21,60 & $22,88^{3}$ \\
Randon Administradora de Consórcios Ltda. & 45.054 & 1,50 & 99,57 \\
Randon Argentina S.A & 66.587 & 2,20 & 99,99 \\
CasterTech Tecnologia e Fundição Ltda. ${ }^{1}$ & $\mathrm{n} / \mathrm{a}$ & $\mathrm{n} / \mathrm{a}$ & 99,99 \\
TOTAL & 3.059 .478 & 100,00 & $\mathrm{n} / \mathrm{a}$ \\
\hline
\end{tabular}

FONTE: RANDON (2009c)

NOTAS: ${ }^{1}$ São consideradas apenas as vendas externas as empresas do conglomerado Randon.

${ }^{2}$ A CasterTech é uma empresa criada para fornecer peças para as empresas do conglomerado Randon. Por isso não aparece na receita consolidada.

${ }^{3}$ Possui outros 53,18\% das suas ações da Master Sistemas Automotivos Ltda.

Ainda em relação à tabela 1, a maior receita individual do conglomerado Randon provém da Randon S. A. Implementos e Participações que produz o principal produto que são os semi-reboques. Apesar de ter sido mostrado no gráfico 1 que as duas principais divisões tem contribuições semelhantes para a receita da empresa, a tabela 1 contra-argumenta 
que a divisão de autopeças tem uma receita melhor distribuída entre as empresas.

Em relação ao mercado externo, o conglomerado não é apenas um exportador de produtos prontos através de escritórios internacionais, mas conta com unidades de montagem e plantas industriais fora do Brasil. Como mostra as tabela 2, a Fras-Le, recentemente abriu plantas industriais nos Estados Unidos e China, em boa parte por que comercializar pastilhas de freio tem menos entraves do que outros produtos, especialmente no mercado de reposição. Os semi-reboques são produzidos no Brasil e Argentina, sendo montados em unidades estrategicamente espalhadas pelo mundo

TABELA 2 - ABRANGÊNCIA GLOBAL DAS OPERAÇÕES DAS EMPRESAS DO CONGLOMERADO RANDON

\begin{tabular}{|c|c|c|}
\hline País & Empresa/Cidade & Tipo de Unidade \\
\hline Brasil & $\begin{array}{r}\text { Guarulhos - São Paulo } \\
\text { Caxias do Sul - Rio Grande do Sul }\end{array}$ & $\begin{array}{l}\text { Matriz } \\
\text { Matriz }\end{array}$ \\
\hline África do Sul & Johannesburg & Escritório Internacional \\
\hline Alemanha & Gelsenkirchen & Escritório Internacional \\
\hline Argélia & $\begin{array}{r}\text { Argel } \\
\text { Fras-le (San Martin - Província de Buenos Aires) }\end{array}$ & $\begin{array}{l}\text { Unidade Montadora } \\
\text { Centro de distribuição }\end{array}$ \\
\hline Argentina & Randon (Rosário) & Unidade Industrial \\
\hline Chile & Santiago & Escritório Internacional \\
\hline China & $\begin{array}{l}\text { Fras-le (Pinghu - Província de Zhejiang) } \\
\text { Fras-le (Shangai - Província de Zhejiang) }\end{array}$ & $\begin{array}{r}\text { Unidade Industrial } \\
\text { Escritório Internacional }\end{array}$ \\
\hline Dubai & $\begin{array}{l}\text { Jebel Ali Free Zone } \\
\text { Randon (Miami - Flórida) }\end{array}$ & $\begin{array}{l}\text { Escritório Internacional } \\
\text { Escritório Internacional }\end{array}$ \\
\hline Estados & Fras-le (Farmington Hills - Michigan) & Centro de distribuição \\
\hline Unidos & Fras-le (Prattville - Alabama) & Unidade Industrial \\
\hline Índia & $\mathrm{n} / \mathrm{a}$ & Escritório Internacional \\
\hline Marrocos & Casa Blanca & Unidade Montadora \\
\hline México & Cidade do México - DF & Escritório Internacional \\
\hline Quênia & Nairobi & Unidade Montadora \\
\hline
\end{tabular}

FONTE: RANDON (2009c)

Em relação às exportações, a tabela 3 revela que a principal exportadora é a Randon implementos devido aos semi-reboques que são os produtos líderes da empresa. Seguida pela Fras-Le porque, como já foi citado, é fácil penetrar em novos mercados com pastilhas e lonas de freios que se desgastam mais rapidamente e precisam ser substituídas periodicamente do que sistemas interiores de freios e suspensão.

O gráfico 3 mostra as exportações do conglomerado Randon por bloco econômico em 2008. Não surpreende que a maior parte das exportações sejam destinadas ao Mercosul e Chile pelos acordos de livre comércio, proximidade geográfica, compatibilidade técnica e cultural de operação. O NAFTA e África vêm empatados. A África demanda mais semireboques e produtos prontos e, por isso, existem tantas unidades montadoras nesse continente como mostra o gráfico 2. O NAFTA e os Estados Unidos demandam 
predominantemente autopeças.

TABELA 3 - EXPORTAÇÕES DO CONGLOMERADO RANDON EM 2008

\begin{tabular}{l|r}
\hline \multicolumn{1}{c|}{ Empresas } & Em milhões de US\$ \\
\hline Randon S.A Implm. E Participações + SP & 137.288 \\
Master Sistemas Automotivos Ltda. & 27.734 \\
Randon Veículos Ltda. & 4.475 \\
Jost Brasil Sistemas Automotivos Ltda. & 9.364 \\
Fras-le S.A & 85.304 \\
Suspensys Sistemas Automotivos Ltda. & 22.800 \\
TOTAL & 286.965 \\
\hline
\end{tabular}

FONTE: RANDON (2009c, p. 16)

GRÁFICO 3 - DISTRIBUIÇÕES DAS EXPORTAÇÕES DO CONGLOMERADO RANDON POR BLOCO ECONÔMICO EM 2008

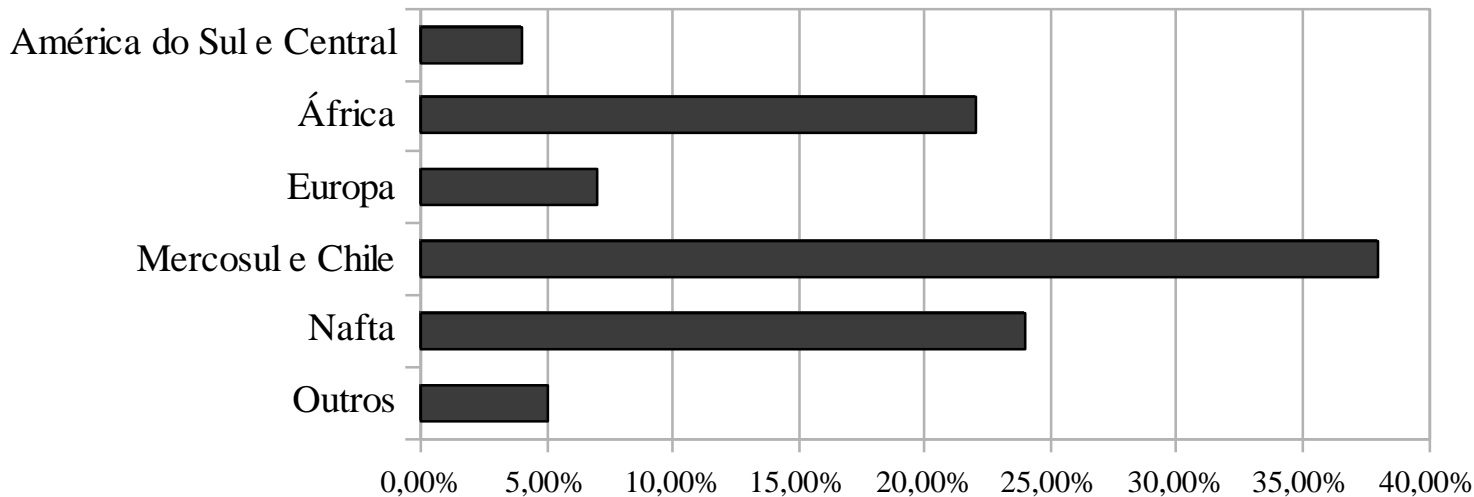

FONTE: RANDON (2009c, p. 16).

\section{CONSIDERAÇÕES FINAIS}

A Randon nasceu como uma empresa familiar no fim da década de 1940 criada pelos irmãos Hercílio e Raul Anselmo Randon, na cidade gaúcha de Caxias do Sul. De um lado, se beneficiaram do ambiente próspero da região para uma firma que prestasse serviços e oferecesse produtos para os caminhões que circulavam em grande fluxo. De outro, não menos importante, souberam se beneficiar da crescente indústria automobilística brasileira e do aprofundamento de uma interligação rodoviária anteriormente inexistente.

Nas décadas de 1950 e 1960, a Randon passou de uma pequena empresa regional para uma grande firma de abrangência nacional, na qual o principal produto, o semi-reboque, se tornou por muito tempo sinônimo de Randon sem concorrentes que ameaçassem sua liderança. Na década de 1970 avançou mais um passo para a sua expansão e modernização ao se transformar numa sociedade anônima e de capital aberto, ampliar sua capacidade produtiva, buscar parceiros, ganhar o mercado externo e diversificar seus nichos de atuação. 
Na década de 1980, as joint ventures se tornaram parte integrante da estratégia de negócio, que foi consolidada na década de 1990 com parcerias junto às transnacionais do setor de autopeças.

No começo da década de 1990, a família criou a empresa DRAMD Administração e Participações Ltda. para tornar-se o acionista controlador do conglomerado Randon. De um lado, evitando que as brigas e instabilidades familiares prejudicassem a empresa e, de outro, dessem mais flexibilidade, transparência e confiabilidade, algo essencial para viabilizar parcerias, atrair investidores e impulsionar a internacionalização e globalização. Assim, o conglomerado Randon conseguiu se tornar um dos maiores grupos privados do país e uma das maiores firmas do setor de transporte a nível mundial, apesar de manter características de uma empresa familiar, tendo o irmão co-fundador Raul Anselmo Randon como presidente e seu filho David Abramo Randon como vice.

\section{REFERÊNCIAS}

RANDON. (2009). Empresas Randon: a história de uma empresa. Disponível em: http://www.randon.com.br/Randon_Implementos/. Acesso em: 28 mar. 2009.

RANDON. (2009b). Institucional Corporativo: perfil das empresas Randon, histórico, a marca. Disponível

em:

http://www.randon.com.br/Randon_Implementos/Institucional/Estrutura.asp?NumFuncio nalidade $=41 \&$ NumCategoria $=238 \&$ NumCategoriaF $=239 \&$ NomeCategoria $=$ Histórico $\&$ Men uLateral=s. Acesso em: 28 mar. 2009.

RANDON. (2009c). Relatório Anual 2008. Disponível em: http://www.mzweb.com.br/randon/web/arquivos/RANDON_Rel_Anual_2008_20090305_ port.pdf. Acesso em: 30 mar. 2009.

RANDON. (2009d). Relação com Investidores. Disponível em: http:/ /www.mzweb.com.br/randon/web/conteudo_pt.asp?idioma $=0 \&$ tipo $=12734 \&$ conta $=2$ 8. Acesso em: 30 mar. 2009.

RANDON. (2009e). Movimentação de valores Imobiliários dos Acionistas Controladores, Administradores e Conselheiros Fiscais da Randon Participações S. A. Disponível em: <cvmweb.cvm.gov.br/SWB/Sistemas/SPW/FRelevantes/Arq/

140A60157A164834AEF49AB85BF5FED8.doc >. Acesso em: 4 abr. 2009. 
